\title{
Biosynthesis Coupled to the Extraction of Geranyl Acetate in a Liquid-Gas System: Optimization of the Transesterification Reaction and Modeling of the Transfer
}

\author{
R. Kirdi, ${ }^{a,{ }^{*}}$ N. Ben Akacha, ${ }^{b}$ and M. Gargouria ${ }^{a}$ \\ ${ }^{a}$ Biocatalysis and Industrial Enzymes Group, Laboratory of Microbial \\ Ecology and Technology, National Institute of Applied Sciences \\ and Technology (INSAT) Tunis, University of Carthage, Tunisia \\ ${ }^{b}$ Laboratory of Natural Substances, National Institute of Research \\ and Physical and Chemical Analysis (INRAP), Biotechnopôle Sidi Thabet, \\ 2020 Ariana, Tunisia
}

doi: 10.15255/CABEQ.2015.2232

Original scientific paper Received: May 22, 2015 Accepted: March 2, 2016

\begin{abstract}
The objective of this paper was to study the production and the mass transfer of geranyl acetate known for its interesting green odor properties. Lipase-catalyzed geranyl acetate production via transesterification reaction with ethyl acetate in organic solvent was investigated. The production was catalyzed by using immobilized lipase from $R h i-$ zomucor miehei, and the recovery was achieved by using solid phase microextraction (SPME) fiber system (50/30 $\mu \mathrm{m}$ DVB/Carboxen/PDMS Coating). The effects of different reaction parameters on transesterification including the enzyme concentration, the substrate molar ratio, the added water, and the reaction time were firstly optimized. A higher yield of $82 \%$ was achieved under near-anhydrous conditions at $55^{\circ} \mathrm{C}$ by using an enzyme concentration of $6 \%$ (w/w reactants), a molar ratio of geraniol to ethyl acetate of 1:5, and a reaction time of $6 \mathrm{~h}$. Immobilized lipase was repeatedly used for four cycles with no decrease in reaction yield. The mass transfer of geranyl acetate from the organic to gas phase was studied theoretically and experimentally, and a transfer yield of $52.3 \%$ was obtained. The simulation showed that the Fuller-Schettler-Giddings model exhibited good correlation with the experimental data.
\end{abstract}

Key words:

geranyl acetate, mass transfer coefficient, modeling, Rhizomucor miehei lipase, transesterification

\section{Introduction}

Terpenic esters are considered as flavor and fragrance compounds of economical interest in the food, cosmetic, and pharmaceutical industries. ${ }^{1,2}$ The broad use of these compounds was worth approximately $23.5 \$$ billion in $2014 .{ }^{3}$ Esters are generally obtained by chemical synthesis or extraction from natural products. However, these methods exhibit low production yields of the desired product and are often expensive for commercial production. $^{4-7}$ Esters of geraniol, especially geranyl acetate, represent a flavor with interesting odor properties. It is the major constituent of numerous essential oils, such as lime oil, which has high economical importance. ${ }^{8}$

The flavor industry is nowadays interested in the use of biotechnological approaches for the production of natural aroma compounds. Enzymatic methods using lipases (triacylglycerol acylhydrolases E.C. 3.1.1.3) as catalysts have been used to

"Corresponding author: youracha@yahoo.fr, tel: 216.71.703.929, fax: 216.71.704.329 produce a large number of commercially important flavor esters. ${ }^{9-11}$ Production may be achieved by direct esterification ${ }^{12-14}$ or by transesterification reactions. ${ }^{15}$ Microbial lipases are used more than lipases derived from plants or animals. ${ }^{16}$ Fungi are the best producers of lipases used in the food industry. ${ }^{17}$

The biotechnological production of geranyl acetate with different sources of lipase has received much attention for many years. Geranyl acetate was produced by the transesterifiation reaction catalyzed by lipase from Candida antarctica in solvent-free medium, ${ }^{18}$ and by direct esterification with membrane-mediated water removal. ${ }^{19}$ Lipase from Candida cylindracea immobilized in sol-gel matrix was proved an efficient catalyst for the production of geranyl acetate by direct esterification reaction. ${ }^{20}$

Damnjanović et al. ${ }^{21}$ have studied the production of geranyl butyrate by using immobilized lipase from Candida rugosa in batch and fluidized bed reactors. These authors have demonstrated that the productivity of geranyl butyrate in the fluidized 
bed reactor was more than five-fold higher than that obtained in the batch system. The fluidized bed reactor is mainly used in continuous industrial biosynthesis of such products. ${ }^{21,22}$

Once produced, the volatile compounds have to be extracted efficiently. However, after their production, such molecules may undergo changes during their extraction. Indeed, the temperature and/or solvents used in the conventional methods to extract the volatile compounds may contribute to their transformation. It is therefore important to develop an efficient and adapted system to extract these molecules with high purity while preventing their degradation. Various methods have been used to improve the extraction of volatile aroma compounds including: distillation ${ }^{18}$, adsorption on resins, ${ }^{23}$ and the pervaporation methods. ${ }^{24}$

Hydrophobicity of many aromatic compounds makes them toxic at high concentrations and can therefore inhibit enzymatic reaction if there is an excess in the medium. The simultaneous production and extraction of volatile products constitute a valuable alternative to avoid enzyme inhibition by the reaction product, and thus increase the yields of production. ${ }^{25}$ Considerable attention has been accorded to the two-phases (liquid-gas) partitioning bioreactor configuration, in recent years, compared to conventional monophasic systems. Bi-phasic configuration has several advantages, such as: limiting the enzyme inhibition by the substrate and/or the product, and allowing a good partition of reactants between phases. The liquid-gas bi-phasic system has been used in several studies. ${ }^{26,27}$ Ben Akacha et $a l .{ }^{26}$ have coupled the synthesis of natural green note aroma compounds to their recovery by bubbling nitrogen, as carrier gas. These authors have demonstrated that the temperature was the most important parameter affecting the transfer of these volatile compounds from liquid to gas phase, and a maximal transfer yield of $77 \%$ had been obtained. ${ }^{26}$

Solid-phase micro-extraction (SPME) was first developed by Pawliszyn.$^{28}$ It is an efficient sampling technique in which the analytes in the sample are directly extracted and concentrated to the extraction fibre. This method allows saving preparation time, disposal costs, as well as improves the detection limits. The SPME has several applications in diverse fields (food, environment, polymers and explosives). The combination of SPME with gas chromatography (GC) or gas chromatography-mass spectrometry (GC-MS) was proven a sensitive and precise method for the analysis of different classes of volatile compounds from different sample matrices. ${ }^{29}$

The purpose of this paper was to study the experimental and theoretical transfer of geranyl ace- tate between liquid and gas phases after its production by lipase-catalyzed transesterification reaction. We were also interested in determining the optimal parameters in the enzymatic reaction such as: enzyme concentration, two-substrate molar ratio, water content and reaction time. In addition to the synthesis of volatile aroma compounds in organic medium, their extraction is also of a crucial. The solid phase microextraction system was used in this study for the continuous extraction of geranyl acetate from the organic phase; where it is enzymatically produced, to the gas phase. In order to evaluate the mass transfer between the two compartments, a detailed mathematical model of this system was developed.

\section{Material and methods}

Immobilized lipase from Rhizomucor miehei (Lipozyme IM-20) was obtained from Novo-Nordisk A/S (Bagsvaerd, Denmark). Geraniol, geranyl acetate were purchased from Sigma-Aldrich (France). Ethyl acetate was from Eurolabo (France), and $n$-heptane was purchased from Panreac Química (Espagne).

\section{Enzyme-catalyzed transesterification reaction}

Ester synthesis was carried out in screw-capped test tubes $(10 \mathrm{~mL})$. The geranyl acetate synthesis was achieved in heptane $(3 \mathrm{~mL})$ in the presence of various concentrations of geraniol and ethyl acetate. The molar ratio of the used substrates (geraniol/ ethyl acetate) was varied (from $1 / 1$ to $1 / 6$ ) and the reactions were catalyzed by using $10 \%$ (w/w reactants) of immobilized lipase from Rhizomucor miehei. The effects of lipase concentration, water content, and incubation time were also studied. The transesterification reactions were conducted at $55^{\circ} \mathrm{C}$ under magnetic stirring $(150 \mathrm{rpm})$. In order to study the effect of incubation time on the production yield of geranyl acetate, samples were withdrawn as a function of time, and were analyzed by gas chromatography. A sample without added lipase and which was incubated under the same conditions was used as control. The study of the immobilized lipase recycling was also investigated by reusing the same enzyme several times. In this case, and after the achievement of lipase reaction, the product was removed and the enzyme in the test tube washed with heptane, and subsequently dried in a desiccator to be reused.

$$
\begin{gathered}
\text { Conversion yield }(\%)= \\
=1-\frac{\text { Final concentration of geraniol }}{\text { Initial concentration of geraniol }} \cdot 100
\end{gathered}
$$




\section{Volatile compounds extraction and analysis}

The geranyl acetate was trapped on SPME fiber $(50 / 30 \mu \mathrm{m} \mathrm{DVB} /$ Carboxen/PDMS Coating) in the gas phase continuously after its biosynthesis, and then thermally desorbed at $220{ }^{\circ} \mathrm{C}$ for 2 minutes in the gas chromatography (GC) injector. The geranyl acetate concentration was then measured by GC. This compound was separated on HP-INNOWAX polyethylene glycol (PEG) $(30 \mathrm{~m} \times 0.25 \mathrm{~mm})$ column. Injector and detector temperatures were set at 220 and $280{ }^{\circ} \mathrm{C}$, respectively. The oven temperature mode was from 80 to $120^{\circ} \mathrm{C}$ at $8^{\circ} \mathrm{C} \mathrm{min}-1$ and then at $10{ }^{\circ} \mathrm{C} \mathrm{min}^{-1}$ up to $220{ }^{\circ} \mathrm{C}$, the final temperature was held for 20 minutes. Helium, the carrier gas, was used at a constant flow rate of $1 \mathrm{~mL} \mathrm{~min}^{-1}$.

\section{Study of geranyl acetate transfer from organic to gas phase}

The rate of geranyl acetate transferred from liquid to gas phase was studied using microextraction on SPME fiber. The produced geranyl acetate was diffused in the organic medium under the concentration gradient. Once produced, this compound was transferred to the gas phase under the geranyl acetate vapor pressure. The transfer concentration was determined after using SPME fiber $(50 / 30 \mu \mathrm{m}$ DVB/Carboxen/PDMS Coating) to extract the volatile compound. SPME fiber was placed in the headspace of the sample for 20 minutes.

The bi-phasic (liquid-gas) medium temperature was maintained at $55{ }^{\circ} \mathrm{C}$ in a thermostat bath, and geranyl acetate transfer to the gas phase was measured after being produced by immobilized lipase in organic phase, as shown in Fig. 1.

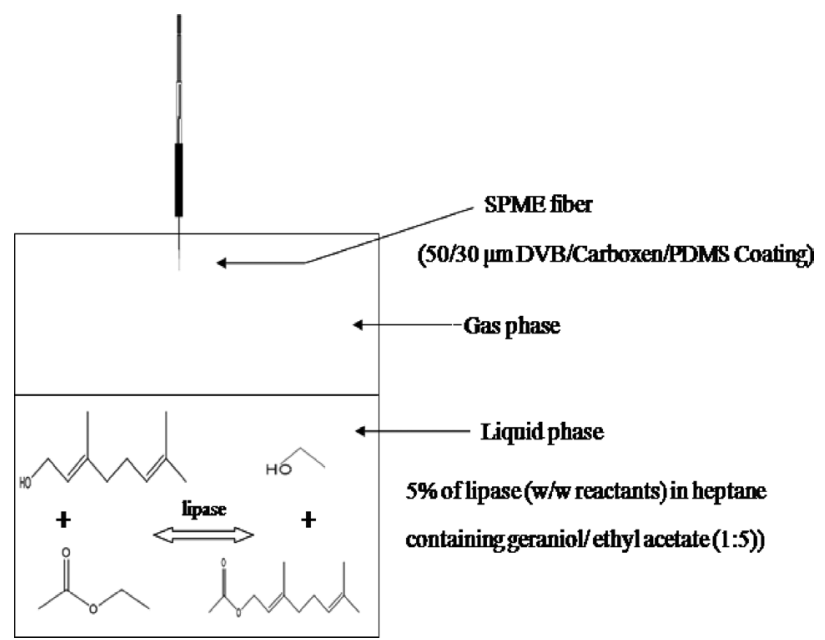

Fig. 1 - Schematic diagram of geranyl acetate production and transfer in liquid-gas bi-phasic system using the solid phase microextraction

\section{Determination of saturating concentration of geranyl acetate in gas phase}

The geranyl acetate was removed from the organic phase ( $n$-heptane) to the gas phase where it was adsorbed on the SPME fiber until reaching saturation. The saturating concentration was determined experimentally in a hermetic flask of $1 \mathrm{~mL}$. Different concentrations of geranyl acetate were diluted in $500 \mu \mathrm{L}$ of $n$-heptane. To determine the saturating concentration, an SPME fiber was completely placed in the head-space for 20 minutes for the geranyl acetate extraction.

\section{Mathematical modeling}

The theoretical models of mass transfer in the liquid phase are intended to allow the analysis of the training of the gaseous compounds through the liquid phase under the influence of a concentration gradient. Since there is a concentration gradient in a fluid, the volatile compound will spontaneously evolve by diffusion to a state of uniform concentration, corresponding to the thermodynamic equilibrium between liquid and gas phases. The geranyl acetate transfer rate from the liquid organic phase ( $n$-heptane) to the gas phase is expressed as:

$$
\frac{\mathrm{d} G_{A}}{\mathrm{~d} t}=K_{L}\left(G_{A s}-G_{A}\right)
$$

where $K_{L}$ is the mass transfer coefficient $\left(\mathrm{m} \mathrm{s}^{-1}\right), G_{A s}$ is the saturating concentration of geranyl acetate in gas phase $(\mathrm{mM})$, and $G_{A}$ is the instantaneous concentration of geranyl acetate in the gas phase.

\section{Mass transfer coefficient}

$$
K_{L}=2 \sqrt{\frac{D_{A B}}{\pi t}}
$$

where $D_{A B}$ represents the coefficient of mass diffusivity of geranyl acetate in the gas phase $\left(\mathrm{m}^{2} \mathrm{~s}^{-1}\right)$.

\section{Mass diffusivity coefficient}

The coefficient of mass diffusivity $D_{A B}$ for binary mixture was theoretically determined using two equations:

The first equation used to calculate $\left(D_{A B}\right)$ was the equation of Hirschfelder-Bird-Spotz modified by Willke-Lee. ${ }^{30}$ This equation is recommended for mixtures of nonpolar gases or of polar with nonpolar gases.

$$
=\frac{10^{-4}\left(1.084-0.249 \sqrt{\frac{1}{M_{A}}+\frac{1}{M_{B}}}\right) T^{\frac{3}{2}} \sqrt{\frac{1}{M_{A}}+\frac{1}{M_{B}}}}{p_{t}\left(r_{A B}\right)^{2} \Omega_{(A, B)}}
$$


where $M_{A}$ represents the molecular weight of $\mathrm{C}_{12} \mathrm{H}_{20} \mathrm{O}_{2}$ (geranyl acetate), $M_{B}$ is the molecular weight of air (gas phase), $T$ is the medium temperature $(\mathrm{K}), p_{t}$ is the pressure $\left(\mathrm{N} \mathrm{m}^{-2}\right), r_{A B}$ is the molecular separation at collision, $\Omega_{D(A, B)}$ is the collisional integral for diffusion of geranyl acetate.

$\Omega_{D(A, B)}$ is the function of the dimensionless temperature $K T / \varepsilon_{A B}$.

The table of Hirschfelder-Bird-Spotz ${ }^{30}$ was used to determine the specific parameters of the compound B:

Air: $M_{B}=29 \mathrm{~g} \mathrm{~mol}^{-1} r_{B}=0.3711 \mathrm{~nm} \varepsilon_{B} / K=78.6 \mathrm{~K}$

For compound $\mathrm{A}\left[\mathrm{C}_{12} \mathrm{H}_{20} \mathrm{O}_{2}\right], \varepsilon_{A} / K, r_{A}, r_{A B}$ and $\varepsilon_{A B} / k$ can be estimated from the following combining equations:

$$
\begin{gathered}
\varepsilon_{A} / K=1.21 T_{b} \\
r_{A}=1.18 \mathrm{~V}^{1 / 3}
\end{gathered}
$$

$V$ is the molar volume of the liquid at normal boiling point $\mathrm{m}^{3} \mathrm{kmol}^{-1}$. This parameter was calculated from the table ${ }^{30}$ and is equal to $0.2664 \mathrm{~m}^{3} \mathrm{kmol}^{-1}$.

$T_{b}$ represents the normal boiling point for geranyl acetate: $515.5 \mathrm{~K}$.

The mixture parameters are then estimated from Eqs. (5), (6), (7), and (8):

$$
\begin{aligned}
& r_{A B}=\frac{r_{A}+r_{B}}{2} \\
& \varepsilon_{A B}=\sqrt{\varepsilon_{A} \varepsilon_{B}}
\end{aligned}
$$

$\varepsilon_{A} / K=623.75, r_{A}=0.759 \mathrm{~nm}, r_{A B}=0.56355 \mathrm{~nm}$ and $\varepsilon_{A B} / K=221.42 \mathrm{~K}$.

For a temperature of $328 \mathrm{~K}$, the dimensionless temperature is $K T / \varepsilon_{A B}=1.48$. The collision integral for diffusion of geranyl acetate was determined using the table of Lennard-Jones potential for the prediction of transport properties of gases. ${ }^{31} \Omega_{D(A, B)}$ determined was of 1.2085. Substitution of this value in Eq. (4) gives:

$$
D_{A B}=2.93 \cdot 10^{-6} \mathrm{~m}^{2} \mathrm{~s}^{-1}
$$

Then Eq. (3) gives: $K_{L}=0.102 \mathrm{~m} \mathrm{~s}^{-1}$.

The molecular diffusion coefficient $\left(D_{A B}\right)$ was calculated by using a second equation for the Fuller-Schettler-Giddings (1966), ${ }^{32}$ this second value allowed calculating the value of $K_{L}$. The $K_{L}$ determined by Eqs. (4) and (9) allowed to conduct the simulation.

$$
D_{A B}=\frac{10^{-3} T^{1.75} \sqrt{\frac{1}{M_{A}}+\frac{1}{M_{B}}}}{p\left[\left(\Sigma V_{A}\right)^{\frac{1}{3}}+\left(\Sigma V_{B}\right)^{\frac{1}{3}}\right]^{2}}
$$

where $M_{A}$ represents the molecular weight of $\mathrm{C}_{12} \mathrm{H}_{20} \mathrm{O}_{2}, M_{B}$ is the molecular weight of air, $T$ is the medium temperature $(\mathrm{K}), p$ is the pressure (atm), $V_{A}, V_{B}$ are the atomic diffusion volumes that can be estimated from volume increments associated with each element in the compound.

The table of Fuller-Schettler-Giddings (1966) ${ }^{32}$ gives the following parameters:

$$
V_{A}=248.98, V_{B}=20.1
$$

where $M_{A}=196.29 \mathrm{~g} \mathrm{~mol}^{-1}$, and $M_{B}=29 \mathrm{~g} \mathrm{~mol}^{-1}$.

Substitution of the preceding values in Eq. (9) gives:

$$
D_{A B}=6.17 \cdot 10^{-6} \mathrm{~m}^{2} \mathrm{~s}^{-1} .
$$

Then Eq. (3) gives: $K_{L}=0.14 \mathrm{~m} \mathrm{~s}^{-1}$.

\section{Modeling and simulation of the transfer}

The concentrations of geranyl acetate transferred from liquid to gas phase were determined experimentally and compared to the theoretical prediction values. The saturating concentration of geranyl acetate in gas phase determined experimentally was introduced into the model and the simulation was achieved by using MATLAB 6.0.

\section{Model validation}

The variation of geranyl acetate concentration transferred as a function of time, according to Eq. (2) was plotted as shown in Fig. 8. The mean relative error between model prediction values and the measured values was calculated as shown in Eq. (10):

$$
\varepsilon(\%)=\frac{1}{n} \sum_{i=1}^{n} \frac{\left|G_{A i}^{\text {measured }}-G_{A i}^{\text {predicted }}\right|}{C_{A i}^{\text {measured }}} \cdot 100
$$

where: $G_{A \mathrm{i}}$ is the transferred geranyl acetate concentration measured or predicted from the model. $n$ is the number of $G_{A i}$ measurements used for model validation.

\section{Results and discussion}

\section{Effects of different parameters on the transesterification reaction}

The effect of enzyme concentration on the yield of geranyl acetate obtained by transesterification was studied, and the results are shown in Fig. 2. The conversion was improved and reached $80 \%$ by using $6 \%$ (w/w reactants) of Rhizomucor miehei lipase (Fig. 2). Yee et al. ${ }^{34}$ obtained a yield of about $96 \%$ after $24 \mathrm{~h}$ of reaction by using 200 units (approximately $11 \% \mathrm{w} / \mathrm{w}$ of reactants) of lipase from Pseudomonas sp. for the transesterification reaction of geraniol $(0.1 \mathrm{M})$ and acetic anhydride $(0.1 \mathrm{M})$. 


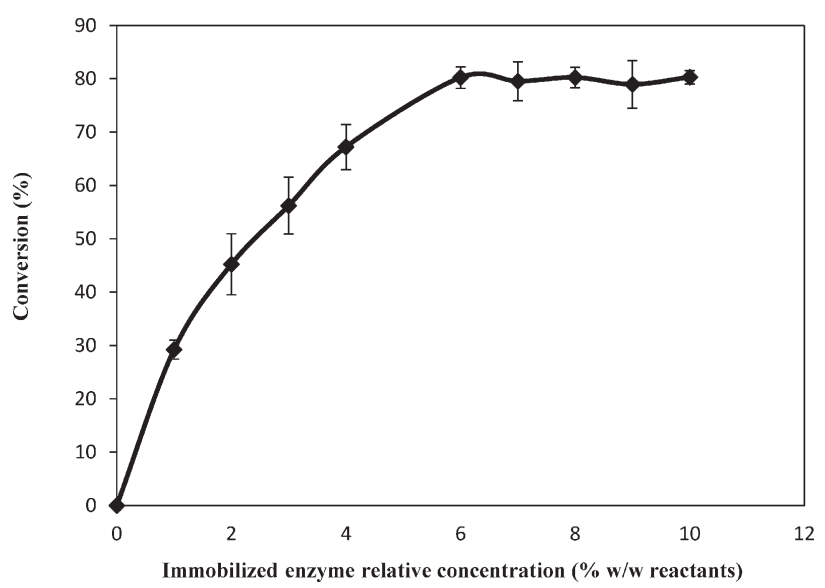

Fig. 2 - Effect of lipase concentration on the Rhizomucor miehei lipase-catalyzed transesterification of geraniol and ethyl acetate. Reaction was conducted for $24 \mathrm{~h}$ at $55{ }^{\circ} \mathrm{C}$ by using geraniol $(0.1 \mathrm{M})$ and ethyl acetate $(0.1 \mathrm{M})$.

Claon et al. ${ }^{14}$ recommended an enzyme load from 2 to $10 \%$ for the synthesis of geranyl esters by lipase from Candida antarctica.

The nature of the substrate used also presents a parameter that affects the transesterification reaction. The terpenic alcohol has an important inhibitory effect on lipase activity in the medium, and this inhibition depends also on the nature of the enzyme. ${ }^{9,34}$ The effect of substrate concentration on the synthesis of geranyl acetate with Rhizomucor miehei has been reported by Chatterjee et al. ${ }^{9}$ These authors have demonstrated that the production of geranyl acetate depended on the nature of the alkyl donor. The production of geranyl acetate was carried out with ethyl and methyl acetate in a solvent-free system using Rhizomucor miehei lipase. A good conversion was found with ethyl acetate, compared to the same reaction realized with methyl acetate. Yee et al. ${ }^{34}$ have also worked on the geranyl acetate production, and have demonstrated that lipase from $R$. miehei was inhibited by increasing the concentration of geraniol up to $0.3 \mathrm{M}$.

The transesterification reaction at different geraniol/ethyl acetate molar ratios was also studied in this work (Fig. 3). Fig. 3 shows that by increasing the geraniol/ethyl acetate molar ratio to $1: 5$, the conversion reached $81 \%$. In fact, the yield of geraniol ester was improved by increasing the concentration of eth$\mathrm{yl}$ acetate. A yield of about $76 \%$ was found by using $10 \%$ of $R$. miehei lipase in a solvent-free system containing a ratio of 1:5 geraniol/ ethyl acetate. ${ }^{9}$

Water has an important impact on transesterification reaction since it is the natural substrate for hydrolysis reaction. ${ }^{36}$ Indeed, enzymes need a layer of water on their upper surface to maintain the conformation required for their catalytic activities. ${ }^{37}$ The choice of solvent is crucial for optimal performance of the transesterification reaction. ${ }^{35}$ Many

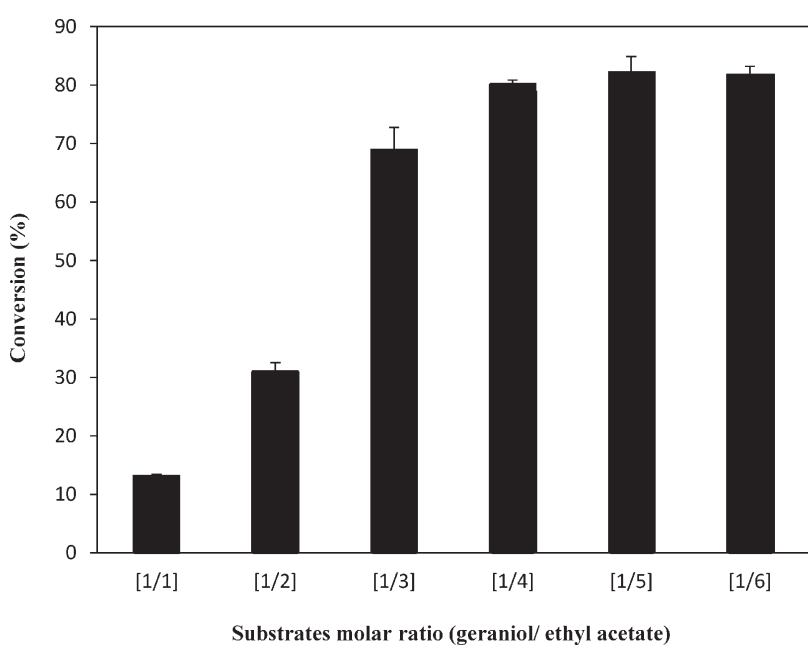

Fig. 3 - Effect of the substrates (geraniol/ethyl acetate) molar ratio on the $R$. miehei lipase-catalyzed trasesterification reaction. The reaction was incubated for $24 \mathrm{~h}$ in $3 \mathrm{~mL}$ of $n$-heptane containing $6 \%$ of lipase ( $w / w$ reactants).

organic compounds of commercial interest have good solubility in organic media compared to aqueous media. The polarity of organic solvents has been proved to affect the change of the energy reactive system, which is associated with the differential salvation of reactants, products, and transition-state species. It is generally reported that the use of solvents with a $\log \mathrm{p} \geq 4.0$ gives higher enzyme activity and better ester synthesis. These solvents have good compatibility with enzymes and they allow preservation of the micro-aqueous layer surrounding the biocatalyst particles. ${ }^{38,39}$ The $n$-heptane $(\log \mathrm{p}=$ 4.0) was therefore used in this study as solvent for geranyl acetate production by Rhizomucor miehei.

The effect of added water on transesterification reaction was studied in this work (Fig. 4). All reactants were dehydrated for $24 \mathrm{~h}$ by using a molecular

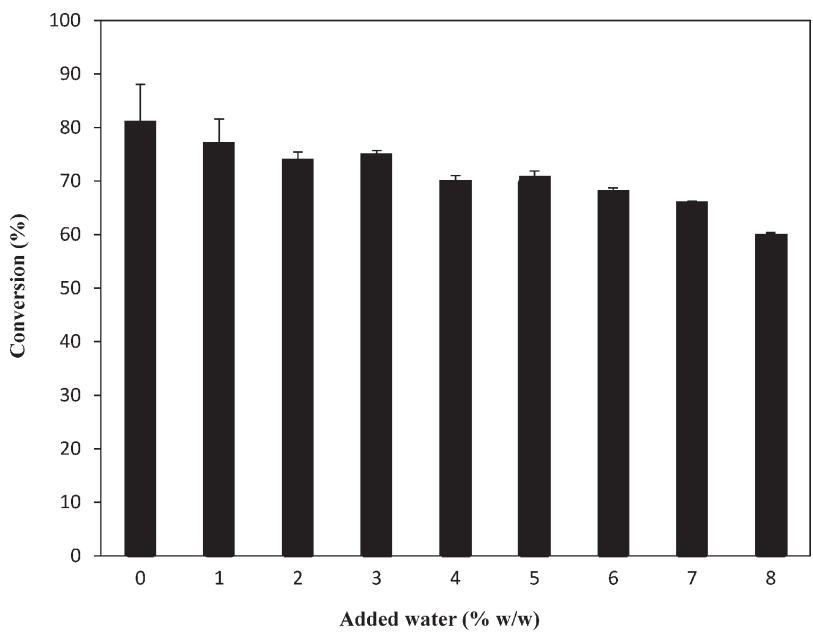

Fig. 4 - Effect of added water on the R. miehei lipase-catalyzed transesterification of geraniol and ethyl acetate. The reaction was realized in $3 \mathrm{~mL}$ of heptane containing geraniol/ ethyl acetate (1:5) and $6 \%$ of lipase (w/w reactants). 
sieve $4 \mathrm{~A}^{\circ}$, and the water content of the enzyme ( $\mathrm{Li}-$ pozyme IM-20) used in this study was approximately $10 \%(\mathrm{w} / \mathrm{w})$. Fig. 4 shows that the addition of water to the reaction medium leads to lower conversion. Under near-anhydrous conditions, the conversion to geranyl-acetate was $80 \%$ (Fig. 4). At $8 \%$ of added water, a drop of $21 \%$ in the yield was observed. This can be explained by the role of the substrate played by water favoring the hydrolysis reaction way. ${ }^{36}$ The hydrolysis reaction is thermodynamically favored when there is an excess of water, and it has also been reported that the lipase is active in nearly anhydrous reaction mixtures ${ }^{5}$. Ghamgui et $a l .{ }^{40}$ have demonstrated that the addition of water in a solvent-free system increases lipase-catalyzed initial rate; however, in hexane, the rate was not affected but the final conversion had decreased by the addition of water.

In order to monitor the reaction progress, we have optimized the time course of the lipase catalyzed transesterification reaction. Fig. 5 shows that the optimum time needed for lipase-catalyzed synthesis of geranyl acetate is $6 \mathrm{~h}$. As shown in Fig. 5, after $6 \mathrm{~h}$ of incubation with $6 \%$ of $R$. miehei lipase, a yield of $82 \%$ was reached. Conversion increased linearly during the first few hours of the transesterification reaction. After $6 \mathrm{~h}$ of reaction, the geranyl acetate synthesis yield stabilized around $80 \%$, and the thermodynamic equilibrium seemed to have been reached. Similar phenomena have been described in previous work. ${ }^{15,18}$ SP 435 from Candida antarctica lipase was used for geranyl acetate production. Optimum yield of $97.7 \%$ was achieved after $8 \mathrm{~h}$ at $30^{\circ} \mathrm{C}$ by using $0.1 \mathrm{M}$ geraniol, $0.1 \mathrm{M}$ vinyl acetate, and 10 $\%$ (w/w of reactants) of enzyme. ${ }^{15}$

The reuse of enzyme in bioconversion plays an important role in reducing the cost of the overall

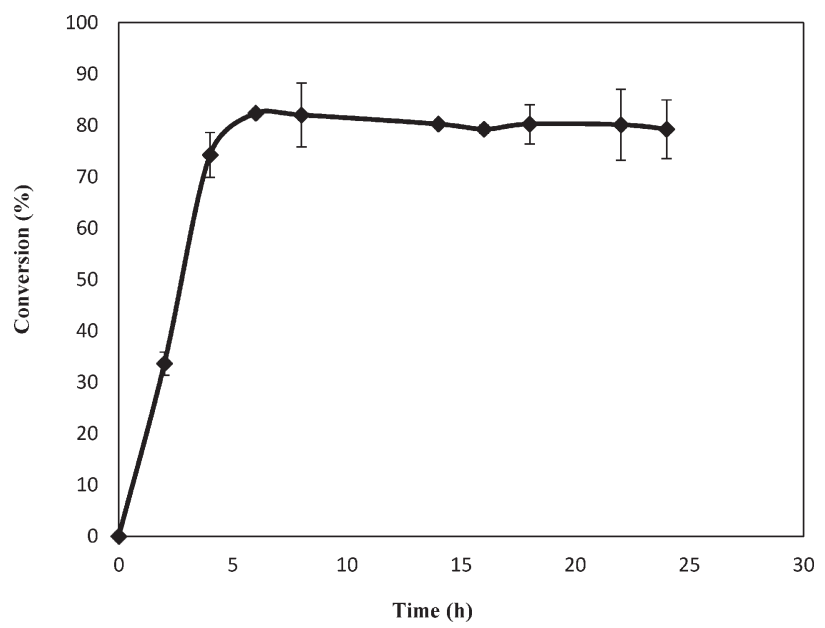

Fig. 5 - Time course of lipase-catalyzed transesterification reaction with Rhizomucor miehei lipase. Samples were withdrawn as a function of time from the reaction medium containing $6 \%$ of lipase ( $w / w$ reactants) in $3 \mathrm{~mL}$ of heptane containing geraniol/ethyl acetate (1:5). process. The ability of immobilized $R$. miehei lipase to be reused was investigated in this study. The reaction was conducted for $24 \mathrm{~h}$ at $55^{\circ} \mathrm{C}$ and the enzyme preparation was reused 9 times in the same conditions. After each run, the enzyme was washed with heptane and the solvent evaporated. Fig. 6 shows that immobilized $R$. miehei lipase was still active after four runs without significant change in transesterification yield. The conversion decreased to $56 \%$ after 9 runs. The decrease of in yield seems to be due to the denaturation of the enzyme after many cycles of use. ${ }^{33}$

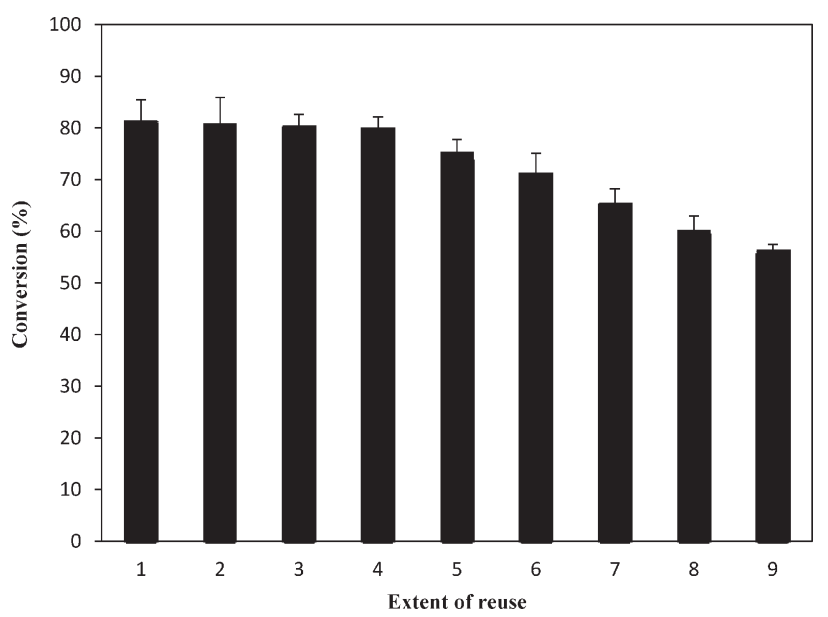

Fig. 6-Effect of the reuse of immobilized R. miehei lipase on the synthesis of geranyl acetate. The reaction was conducted for $24 \mathrm{~h}$ in $3 \mathrm{~mL}$ of heptane containing geraniol/ethyl acetate (1:5) and $6 \%$ of lipase ( $w / w$ reactants).

\section{Theoretical study of geranyl acetate transfer from bioconversion liquid phase to gas phase}

Mathematical modeling is an important means that allows the understanding of the complex behavior of different biological systems. This mathematical approach allows validation of all the studied steps of the process. It allows optimization of the process of enzyme catalysis, and improvement of the transfer that takes place in the bioreactor. This work consists of the study of geranyl acetate mobility, and especially the mass transfer between the liquid organic phase and the gas phase, which occupies the headspace where volatile molecules are specifically detected by SPME fiber (Fig. 1). The rate of geranyl acetate transfer from liquid organic phase to gas phase in the bi-phasic medium (heptane/air) was studied by using Eq. (2). The mathematical modeling of biological systems is important for understanding their complex behavior. The simulation was applied to predict the performance of the two-phase partitioning reactor by analyzing the influence of the mass transport conditions. With improved knowledge of this phenomenon, the mass transfer of geranyl acetate in the two-phase system 
can be predicted as well as help in the better understanding of the process. The extraction approach using liquid/gas system can serve later for the recovery of esters produced in enzymatic reactors.

In order to study the theoretical transfer of the desired compound, it was necessary to determine two parameters: (i) the mass transfer coefficient $\left(K_{L}\right)$ which was theoretically calculated by using Eq. (3), and the saturating concentration of geranyl acetate which was determined experimentally by using the SPME fiber. The saturating head space concentration of geranyl acetate of $2.2 \mathrm{mM}$ was determined from Fig. 7.

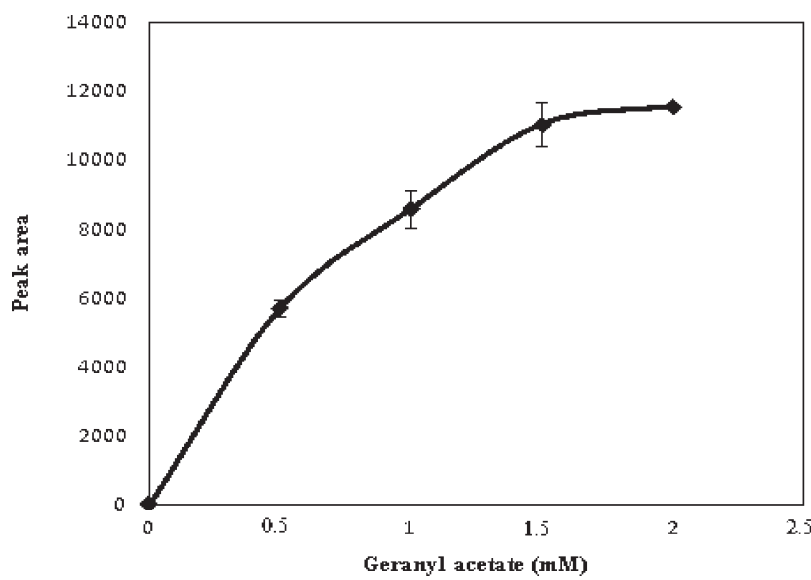

Fig. 7 - Saturating geranyl acetate concentration in gas phase. The SPME fiber; completely placed in head-space for $20 \mathrm{~min}$, allowed measurement of the saturating concentration of geranyl acetate at $55^{\circ} \mathrm{C}$.

The progress curve of the geranyl acetate transferred to the gas phase during conversion was studied in the bi-phasic system at the conditions of synthesis previously optimized.

Two models that allow to distinguish the molecular diffusion mechanism of geranyl acetate were used to determine the diffusion coefficient and therefore to simulate the transfer in the bi-phasic system (Eqs. (4) and (9)). These two models allowed simulation of the evolution of geranyl acetate in the system as a function of time. The coefficient of the mass transfer was obtained theoretically, and the saturating geranyl acetate concentration was experimentally determined. The results of the simulated transfer and the experimental data are compared in Fig. 8. Fig. 8 shows good correspondence between the theoretical evolution obtained by simulation of the geranyl acetate and the experimental results. The mean relative error between model prediction values and the measured values is shown in Table 1. Table 1 indicates that the average difference between the experimental and the calculated values for Willke-Lee model is less satisfactory with a difference of $33 \%$, compared with Fuller-Schettler-Giddings model where the difference is $10 \%$.

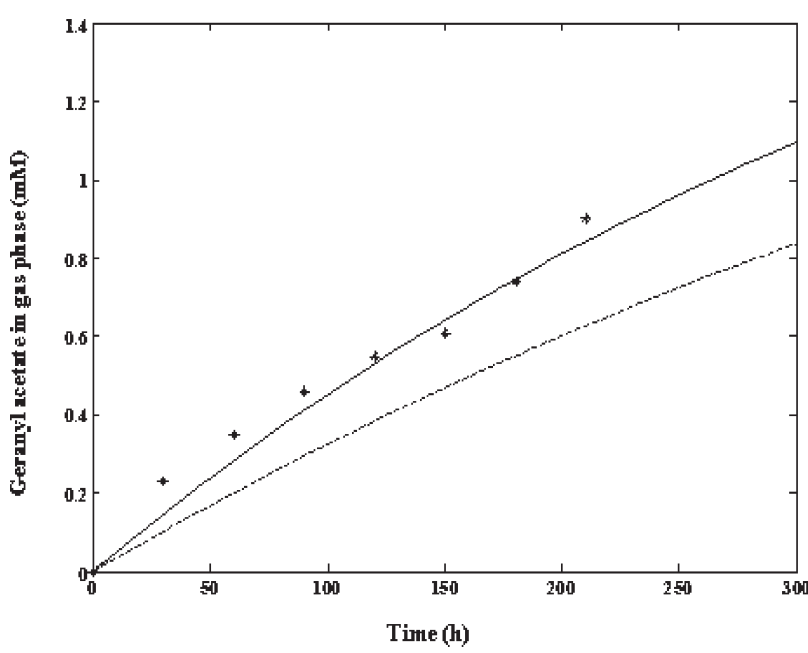

Fig. 8 - Progress curve of geranyl acetate produced by lipase-catalyzed transesterification reaction and transferred from the liquid to the gas phase at $55{ }^{\circ} \mathrm{C}$ using $6 \%$ of lipase $(w / w$ reactants) and geraniol/ethyl acetate molar ratio (1:5). (***) experimental results, (-) simulation obtained by using $K_{L}=$ $0.14 \mathrm{~m} \mathrm{~s}^{-1}$, (- - -) simulation obtained by using $K_{L}=0.10 \mathrm{~m} \mathrm{~s}^{-1}$.

The geranyl acetate transfer to the gas phase seems to be subsequent to its biosynthesis in the same reactor. After $2 \mathrm{~h}$ of reaction catalyzed by lipase, the geranyl acetate concentration reached $0.58 \mathrm{mM}$, corresponding to a yield of synthesis/extraction of 52.3 \%. As shown in Fig. 8, the second model (Eq. 9) permitted to obtain a good correspondence between the experimentally determined results and the simulation with the mean relative error of $10 \%$. In this case, the modeled rate agreed with the experimentally determined rate. The diffusion coefficient $\left(D_{A B}\right)$ depends on temperature, pressure, and the nature of the component of the system. ${ }^{30}$ Indeed, expressions estimating $D_{A B}$ are based on considerations of the kinetic theory of gases. The first model (Eq. 4) gives lower diffusion coefficient $\left(D_{A B}\right)$ value $\left(2.93 \cdot 10^{-6} \mathrm{~m}^{2} \mathrm{~s}^{-1}\right)$ compared to the second model $\left(6.17 \cdot 10^{-6} \mathrm{~m}^{2} \mathrm{~s}^{-1}\right)$. This difference is mainly due to the variables taken into account in the Eq. (4), which is recommended for mixtures of nonpolar gases. The estimation of $D_{A B}$ from Willke-Lee model is based on different variables, such as: molecular separation collision, energy of molecular attraction which depends on gas properties. Whereas, the Eq. (9) uses the molecular volumes of constituent species at normal boiling points. Generally, all these variables are estimated empirically for each component of the studied systems.

Table 1 - Mean relative (\%) errors between measured and predicted geranyl acetate transferred concentration calculated according to two models and the measured values

\begin{tabular}{c|c|c}
\hline Model & Willke-Lee & $\begin{array}{c}\text { Fuller-Schettler- } \\
\text { Giddings }\end{array}$ \\
\hline$\varepsilon(\%)$ & 33.43 & 10.41 \\
\hline
\end{tabular}




\section{Conclusion}

Lipase-catalyzed synthesis of geranyl acetate in organic solvent was studied in this research. Under the optimal reaction conditions, the geranyl acetate yield reached up to $82 \%$ after $6 \mathrm{~h}$ of transesterification reaction. The research on lipase operational stability indicated that this enzyme can be repeatedly used for four cycles without decrease in conversion. Moreover, a simultaneous geranyl acetate production and extraction in a bi-phasic system was studied. A significant transfer yield of $52.3 \%$ was obtained after $2 \mathrm{~h}$ of reaction time. Simulation of the reaction product in a heterogeneous system was conducted by using two models. The results showed good correlation by using Fuller-Schettler-Giddings model (1966). This model allows distinguishing the molecular diffusion mechanism of the reaction product, compared to the Willke-Lee model. Based on the obtained results, this study may guide us to the concept of a bi-phasic reactor that allows enhancement of the yield of production, by coupling the synthesis to the extraction of the desired product.

\section{ACKNOWLEDGMENTS}

This research was supported by the Ministry of High Education and Scientific Research of Tunisia. The authors are grateful to the Ministry of Higher Education and Scientific Research of Algeria for their financial support during this research. The authors thank Miss Faten Fourati for English text improvement.

\section{Abbreviations}

$D_{A B}-$ coefficient of mass diffusivity of geranyl acetate in gas phase, $\mathrm{m}^{2} \mathrm{~s}^{-1}$

$G_{A s}$ - aturating concentration of geranyl acetate in gas phase, $\mathrm{mM}$

$G_{A} \quad$ - instantaneous concentration of geranyl acetate in gas phase, $\mathrm{mM}$

$K_{L} \quad-$ mass transfer coefficient, $\mathrm{m} \mathrm{s}^{-1}$

$M_{i} \quad-$ molecular weight of molecule i, $\mathrm{g} \mathrm{mol}^{-1}$

$p \quad-$ pressure, $\mathrm{N} \mathrm{m}^{-2}$ or atm

$r_{A B}-$ molecular separation at collision, $\mathrm{nm}$

$T \quad$ - medium temperature, $\mathrm{K}$

$V$ - molar volume of the liquid at normal boiling point, $\mathrm{m}^{3} \mathrm{kmol}^{-1}$

$\Omega_{D(A, B)}$ - collisional integral for diffusion of geranyl acetate, it is a function of the dimensionless temperature.

\section{References}

1. Bluemke, W., Schrader, J., Integrated bioprocess for enhanced production of natural flavors and fragrances by $\mathrm{Cer}$ atocystis moniliformis, Biomol. Eng. 17 (2001) 137. doi: http://dx.doi.org/10.1016/S1389-0344(01)00072-7

2. Liaquat, M., Apenten, R. K. O., Synthesis of low molecular weight flavor esters using plant seedling lipases in organic media, J. Food Sci. 65 (2000) 295. doi: http://dx.doi.org/10.1111/j.1365-2621.2000.tb15996.x

3. Yan, H.-D., Zhang, Q., Wang, Z., Biocatalytic synthesis of short-chain flavor esters with high substrate loading by a whole-cell lipase from Aspergillus oryzae, Catal. Commun. 45 (2014) 59. doi: http://dx.doi.org/10.1016/j.catcom.2013.10.018

4. Romero, M. D., Calvo, L., Alba, C., Daneshfar, A., Ghaziaskar H. S., Enzymatic synthesis of isoamyl acetate with immobilized Candida antarctica lipase in $n$-hexane, Enzyme Microb Technol. 37 (2005) 42. doi: http://dx.doi.org/10.1016/j.enzmictec.2004.12.033

5. Hari Krishna, S., Divakar, S., Prapulla, S. G., Karanth, N. $G$., Enzymatic synthesis of isoamyl acetate using immobilized lipase from Rhizomucor miehei, J. Biotechnol. 87 (2001) 193. doi: http://dx.doi.org/10.1016/S0168-1656(00)00432-6

6. Ozyilmaz, G., Gezer, E., Production of aroma esters by immobilized Candida rugosa and porcine pancreatic lipase into calcium alginate gel, J Mol Catal B: Enzym. 64 (2010) 140 .

doi: http://dx.doi.org/10.1016/j.molcatb.2009.04.013

7. Franssen, M. C. R., Alessandrini, L., Terraneo, G., Biocatalytic production of flavours and fragrances, J. Pure Appl. Chem. 77 (2005) 273. doi: http://dx.doi.org/10.1351/pac200577010273

8. Clark, B. C., Chamblee, T. S., Acid-catalyzed reactions of citrus oils and other terpene-containing flavors, In: Charalambous, G. (Ed.), Off-flavors in foods and beverages, Elsevier., Amsterdam, 1992, pp 229-285. doi: http://dx.doi.org/10.1016/B978-0-444-88558-6.50015-5

9. Chatterjee, T., Bhattacharyya, D. K., Synthesis of monoterpene esters by alcoholysis reaction with Mucor miehei lipase in a solvent-free system, J. Am. Oil Chem. Soc. 75 (1998) 651. doi: http://dx.doi.org/10.1007/s11746-998-0079-7

10. Peres, C., Marco, D. R., Da Silva, G., Barreiros, S., Water activity effects on geranyl acetate synthesis catalyzed by Novozym in Supercritical ethane and in supercritical carbon dioxide, J. Agric. Food Chem. 51 (2003) 1884. doi: http://dx.doi.org/10.1021/jf026071u

11. Grosso, C., Ferreira-Dias, S., Pires-Cabral, P., Modelling and optimization of ethyl butyrate production catalysed by Rhizopus oryzae lipase, J. Food Eng. 115 (2013) 475. doi: http://dx.doi.org/10.1016/j.jfoodeng.2012.08.001

12. Couto, R., Vidinha, P., Peres, C., Ribeiro, A. S., Ferreira, O., Oliveira, M. V., Macedo, E. A., Loureiro, J. M., Barreiros, $S$., Geranyl acetate synthesis in a packed-bed reactor catalyzed by Novozym in supercritical carbon dioxide and in supercritical ethane, Ind. Eng. Chem. Res. 50 (2011) 1938. doi: http://dx.doi.org/10.1021/ie101489j

13. Langrand, G., Rondot, N., Triantaphylides, C., Baratti, J., Short chain flavour esters synthesis by microbial lipases, Biotechnol. Lett. 12 (1990) 581. doi: http://dx.doi.org/10.1007/BF01030756

14. Claon, P. A., Akoh, C. C., Enzymatic synthesis of geranyl acetate in $n$-hexane with Candida antarctica lipase, J. Am. Oil Chem. Soc. 71 (1994) 575. doi: http://dx.doi.org/10.1007/BF02540581 
15. Akoh, C. C., Yee, L. N., Lipase-catalyzed transesterification of primary terpene alcohols with vinyl esters in organic media, J. Mol. Catal. B: Enzym. 4 (1998) 149. doi: http://dx.doi.org/10.1016/S1381-1177(97)00029-5

16. Adham, N. Z., Ahmed, E. M., Extracellular lipase of Aspergillus niger NRRL3; production, partial purification and properties. Indian J. Microbiol. 49 (2009) 77. doi: http://dx.doi.org/10.1007/s12088-009-0004-2

17. Falony, G., Armas, J. C., Mendoza, J. C. D., Hernández, J. L. M., Production of extracellular lipase from Aspergillus niger by solid-state fermentation, Food Technol. Biotechnol. 44 (2006) 235.

18. Gryglewicz, S., Jadownicka, E., Czerniak, A., Lipase catalysed synthesis of aliphatic, terpene and aromatic esters by alcoholysis in solvent-free medium, Biotechnol. Lett. 22 (2000) 1379.

doi: http://dx.doi.org/10.1023/A:1005600631600

19. Bartling, K., Thompson, J. U. S., Pfromm, P. H., Czermak, $P$., Rezac, M. E., Lipase-catalyzed synthesis of geranyl acetate in $n$-hexane with membrane-mediated water removal, Biotechnol. Bioeng. 75 (2001) 676. doi: http://dx.doi.org/10.1002/bit.1193

20. Chen, J. P., Lin, W. S., Chang, M. F., Synthesis of geranyl acetate by esterification with lipase entrapped in hybrid solgel formed within nonwoven fabric, J. Am. Oil. Chem. Soc. 79 (2002) 309. doi: http://dx.doi.org/10.1007/s11746-002-0479-5

21. Damnjanović, J. J., Žuža, M. G., Savanović, J. K., Bezbradica, D. I., Mijin, D. Ž., Bošković-Vragolović, N., Knežević-Jugović, Z. D., Covalently immobilized lipase catalyzing high-yielding optimized geranyl butyrate synthesis in a batch and fluidized bed reactor, J. Mol. Catal. B: Enzym. 75 (2012) 50

doi: http://dx.doi.org/10.1016/j.molcatb.2011.11.009

22. Mesa-Pérez, J. M., Cortez, L. A. B., Marín-Mesa, H. R., Rocha, J. D., Peláez-Samaniego, M. R., Cascarosa, E., A statistical analysis of the auto thermal fast pyrolysis of elephant grass in fluidized bed reactor based on produced charcoal, Appl. Therm. Eng. 65 (2014) 322. doi: http://dx.doi.org/10.1016/j.applthermaleng.2013.12.072

23. Hua, D., Ma, C., Song, L., Lin, S., Zhang, Z., Deng, Z., Xu, $P$., Enhanced vanillin production from ferulic acid using adsorbent resin, Appl. Microbiol. Biotechnol. 74 (2007) 783. doi: http://dx.doi.org/10.1007/s00253-006-0735-5

24. Lamer, T., Spinnler, H. E., Souchon, I., Voilley, A., Extraction of benzaldehyde from fermentation broth by pervaporation, Process Biochem. 31 (1996) 533. doi: http://dx.doi.org/10.1016/0032-9592(95)00098-4

25. Ben Akacha, N., Gargouri, M., Microbial and enzymatic technologies used for the production of natural aroma compounds: Synthesis, recovery modelling, and bioprocesses, Food Bioprod. Process. 94 (2015) 675. doi: http://dx.doi.org/10.1016/j.fbp.2014.09.011

26. Ben Akacha, N., Guizani, O. E., Gargouri, M., Improvement and modeling of hexenal transfer in liquid-gas reactor, Appl. Biochem. Biotechnol. 143 (2007) 276. doi: http://dx.doi.org/10.1007/s12010-007-8020-3
27. Monteil, C., Guerbet, M., Le Prieur, E., Morin, J. P., Jouany, J. M., Fillastre, J. P., Characterization of precision-cut rat Lung Slices in a Bi-phasic gas/ liquid exposure system: effect of $\mathrm{O}_{2}$, Toxicol. In Vitro 13 (1999) 467. doi: http://dx.doi.org/10.1016/S0887-2333(99)00011-9

28. Shahtaheri, S. J., Heidari, H. R., Golbabaei, F., Alimohammadi, M., Froshani, A. R., Solid phase microextraction for trace analysis of benzene in environmental monitoring, Iran, J. Environ. Health. Sci. Eng. 3 (2006) 169.

29. Stashenko, E. E., Martínez, J. R., Sampling volatile compounds from natural products with headspace/solid-phase micro-extraction, J. Biochem. Biophys. Methods 70 (2007) 235.

doi: http://dx.doi.org/10.1016/j.jbbm.2006.08.011

30. Terybal, R. E., Mass-transfer operations. McGraw-Hill, New York, 1980, 31-33.

31. Bird, R. B., Stewart, W. E., Lightfoot, E. N., Transport phenomena, John Wiley \& Sons, New York, 2007., 863-866.

32. Fuller, E. N., Schettler, P. D., Giddings, J. C., A new method for prediction of binary gas-phase diffusion coefficients, Ind. Eng. Chem. 58 (1996) 19.

33. Ghamgui, H., Karra-Chaâbouni, M., Bezzine, S., Miled, N., Gargouri, Y., Production of isoamyl acetate with immobilized Staphylococcus simulans lipase in a solvent-free system, Enzyme Microb. Technol. 38 (2006) 788. doi: http://dx.doi.org/10.1016/j.enzmictec.2005.08.011

34. Yee, L. N., Akoh, C. C., Enzymatic synthesis of geranyl acetate by transesterification with acetic anhydride as acyl donor, J. Am. Oil Chem. Soc. 73 (1996) 1379. doi: http://dx.doi.org/10.1007/BF02523500

35. Divakar, S., Manohar, B., Use of lipases in the industrial production of esters. In: Polaina, J., MacCabe, A. P. (Eds.), Industrial Enzymes: Structure, Function and Applications, Springer, The Netherland, 2007, pp 283-300. doi: http://dx.doi.org/10.1007/1-4020-5377-0_17

36. Klibanov, A. M., Why are enzymes less active in organic solvents than in water?, Trends Biotechnol. 15 (1997) 79. doi: http://dx.doi.org/10.1016/S0167-7799(97)01013-5

37. Lopez, M., Kurkal-Siebert, V., Dunn, R. V., Tehei, M., Finney, J. L., Smith, J. C., Daniel, R. M., Activity and dynamics of an enzyme, Pig Liver Esterase, in near-Anhydrous conditions, Biophys J. 99 (2010) 62. doi: http://dx.doi.org/10.1016/j.bpj.2010.07.066

38. Hari Krishana, S., Divakar, S., Prapulla, S. G., Karanth, N. $G$., Enzymatic synthesis of isoamyl acetate using immobilized lipase from Rhizomucor miehei, J. Biotechnol. 87 (2001) 193. doi: http://dx.doi.org/10.1016/S0168-1656(00)00432-6

39. Rivail, J. L., Rinalidi. D., Liquid state quantum chemistry: Computational applications of the polarizable continuum models. In: Leszczynski, J. (Ed.), Computational Chemistry, Review of Current Trends, World Scientific, New York, 1996, pp. 139-174. doi: http://dx.doi.org/10.1142/97898128303640004

40. Ghamgui, H., Karra-Chaâbouni, M., Gargouri, Y., 1-Butyl oleate synthesis by immobilized lipase from Rhizopus ory$z a e$ : a comparative study between $n$-hexane and solvent-free system, Enzyme Microb. Technol. 35 (2004) 355. doi: http://dx.doi.org/10.1016/j.enzmictec.2004.06.002 